\title{
Impacts of ramping inflexibility of conventional generators on strategic operation of energy storage facilities
}

Nasrolahpour, Ehsan; Kazempour, Jalal; Zareipour, Hamidreza; Rosehart, William D.

Published in:

IEEE Transactions on Smart Grid

Link to article, DOI:

10.1109/TSG.2016.2586892

Publication date:

2018

Document Version

Peer reviewed version

Link back to DTU Orbit

Citation (APA):

Nasrolahpour, E., Kazempour, J., Zareipour, H., \& Rosehart, W. D. (2018). Impacts of ramping inflexibility of conventional generators on strategic operation of energy storage facilities. IEEE Transactions on Smart Grid, 9(2), 1334 - 1344. https://doi.org/10.1109/TSG.2016.2586892

\section{General rights}

Copyright and moral rights for the publications made accessible in the public portal are retained by the authors and/or other copyright owners and it is a condition of accessing publications that users recognise and abide by the legal requirements associated with these rights.

- Users may download and print one copy of any publication from the public portal for the purpose of private study or research.

- You may not further distribute the material or use it for any profit-making activity or commercial gain

- You may freely distribute the URL identifying the publication in the public portal 


\title{
Impacts of Ramping Inflexibility of Conventional Generators on Strategic Operation of Energy Storage Facilities
}

\author{
Ehsan Nasrolahpour, Student Member, IEEE, Jalal Kazempour, Member, IEEE, \\ Hamidreza Zareipour, Senior Member, IEEE, and William D. Rosehart, Senior Member, IEEE
}

\begin{abstract}
This paper proposes an approach to assist a pricemaker merchant energy storage facility in making its optimal operation decisions. The facility operates in a pool-based electricity market, where the ramping capability of other resources is limited. Also, wind power resources exist in the system. The merchant facility seeks to maximize its profit through strategic inter-temporal arbitrage decisions, when taking advantage of those ramp limitations. The market operator, on the other hand, aims at maximizing the social welfare under wind power generation uncertainty. Thus, a stochastic bi-level optimization model is proposed, taking into account the interactions between the storage facility and the market operator, and the existing market opportunities for the storage facility. The proposed bilevel model is then transformed into a Mathematical Program with Equilibrium Constraints (MPEC) that can be recast as a Mixed-integer Linear Programming (MILP) problem. Different case studies are presented and discussed using a six-bus illustrative example and the IEEE one-area reliability test system to evaluate the performance of the proposed approach.
\end{abstract}

Index Terms-Price-maker energy storage system, Pool strategy, Mathematical Program with Equilibrium Constraints (MPEC) NOMENCLATURE
A. Indices and Sets
$t \quad$ Index of hours running from 1 to $N_{t}$
$w \quad$ Index of scenarios running from 1 to $N_{w}$
$g \quad$ Index of conventional generators running from 1 to $N_{g}$
$k \quad$ Index of wind power units running from 1 to $N_{k}$
$s \quad$ Index of energy storage systems running from 1 to $N_{s}$
$d \quad$ Index of load demands running from 1 to $N_{d}$
$i, j \quad$ Indices of buses running from 1 to $N_{i}$ and $N_{j}$, respectively
$\Psi_{i} \quad$ Sets of buses adjacent to bus $i$
$Q_{g} \quad$ Mapping the conventional generators into the buses
$Q_{k} \quad$ Mapping the wind power units into the buses
$Q_{s} \quad$ Mapping the energy storage systems into the buses
$Q_{d} \quad$ Mapping the load demands into the buses
B. Parameters
$M C_{s}^{d i s} \quad$ Marginal cost of energy storage system $s$ in the discharging mode, $(\$ / \mathrm{MWh})$

This research project has been partially funded by an NSERC Canada Research grants. E. Nasrolahpour, H. Zareipour, and W. D. Rosehart are with the Department of Electrical and Computer Engineering, Schulich School of Engineering, University of Calgary, Calgary, AB, Canada T2N 1N4 (e-mail: enasrola@ucalgary.ca; h.zareipour@ucalgary.ca; rosehart@ucalgary.ca).

J. Kazempour is with the Technical University of Denmark, Kgs. Lyngby, Denmark (e-mail: seykaz@elektro.dtu.dk).
$M C_{s}^{c h} \quad$ Marginal cost of energy storage system $s$ in the charging mode, (\$/MWh)

$M C_{g} \quad$ Marginal cost of conventional generator $g$, (\$/MWh)

$P_{s}^{d i s, \max }$ Maximum limit on injected power of energy storage system $s$ in the discharging mode, (MW)

$P_{s}^{c h, \max }$ Maximum limit on stored power of energy storage system $s$ in the charging mode, (MW)

$E_{s}^{\max } \quad$ Maximum limit on stored energy of energy storage system $s,(\mathrm{MWh})$

$E_{s}^{i n i} \quad$ Initial value of stored energy of energy storage system $s$, (MWh)

$\alpha_{s} \quad$ A non-negative factor to control stored energy of energy storage system $s$ for the the next time horizon.

$\eta_{s} \quad$ Efficiency of energy storage system $s$

$P_{g}^{\max } \quad$ Capacity of conventional generator $g$, (MW)

$P_{g}^{i n i} \quad$ Initial value of generated power of conventional generator $g$, (MW)

$R U_{g}^{\max }$ Maximum limit on ramp up of conventional generator $g(\mathrm{MW} / \mathrm{h})$

$R D_{g}^{\max }$ Maximum limit on ramp down of conventional generator $g(\mathrm{MW} / \mathrm{h})$

$P_{k, t, w}^{f o r} \quad$ Forecasted generation of wind power unit $k$ at time $t$ under scenario $w$, (MW)

$P_{d, t}^{\max } \quad$ Maximum load demand of consumer $d$ at time $t$, (MW)

$U_{d, t} \quad$ Bid price of load demand $d$ at time $t,(\$ / \mathrm{MWh})$

$B_{i, j} \quad$ Susceptance of line connected bus $i$ to bus $j,\left(\Omega^{-1}\right)$

$P L_{i, j}^{\max }$ Transmission capacity of line connected bus $i$ to bus $j$, (MW)

$\Phi_{w} \quad$ probability of scenario $w$

C. Variables

$u_{s, t}^{\text {dis }} \quad$ Binary decision variable to indicate if energy storage system $s$ is in the discharging mode at time $t$

$u_{s, t}^{c h} \quad$ Binary decision variable to indicate if energy storage system $s$ is in the charging mode at time $t$

$u_{s, t}^{i d l} \quad$ Binary decision variable to indicate if energy storage system $s$ is in the idle mode at time $t$

$\bar{p}_{s, t}^{\text {dis }} \quad$ Quantity offer by energy storage system $s$ in the discharging mode at time $t,(\mathrm{MW})$

$\bar{p}_{s, t}^{c h} \quad$ Quantity bid by energy storage system $s$ in the charging mode at time $t$, (MW)

$p_{g, t, w} \quad$ Power generated by conventional generator $g$ at time $t$ under scenario $w$, (MW)

$p_{k, t, w} \quad$ Power generated by wind power unit $k$ at time $t$ under scenario $w,(\mathrm{MW})$ 


$\begin{array}{ll}p_{s, t, w}^{d i s} & \begin{array}{l}\text { Power injected by energy storage system } s \text { in } \\ \text { the discharging mode at time } t \text { under scenario } \\ \end{array} \\ p_{s, t, w}^{c h} & \begin{array}{l}\text { Power stored by energy storage system } s \text { in } \\ \text { the charging mode at time } t \text { under scenario } w,\end{array} \\ & (\mathrm{MW}) \\ o_{s, t}^{d i s} & \text { Price offer by energy storage system } s \text { in the } \\ & \text { discharging mode at time } t,(\$ \mathrm{MWh}) \\ o_{s, t}^{c h} & \text { Price bid by energy storage system } s \text { in the } \\ & \text { charging mode at time } t,(\$ \mathrm{MWh}) \\ e_{s, t, w} & \begin{array}{l}\text { Energy stored in energy storage system } s \text { at time } \\ t \text { under scenario } w,(\mathrm{MWh})\end{array} \\ p_{d, t, w} & \begin{array}{l}\text { Power consumed by load demand } d \text { at time } t \\ \text { under scenario } w,(\mathrm{MW})\end{array} \\ \delta_{i, t, w} & \begin{array}{l}\text { Voltage angle of bus } i \text { at time } t \text { under scenario } \\ w,(\text { rad) }\end{array} \\ \mu, \lambda & \begin{array}{l}\text { Dual variables corresponding to the lower-level } \\ \text { constraints. See Section (II-B for details. }\end{array}\end{array}$

\section{INTRODUCTION}

Large-scale wind power integration and the associated production uncertainty and variability introduce operational challenges in power systems operation [1]. To manage the issues associated with wind power generation, the concepts of operational flexibility and ramping products are being explored by system operators in electricity markets (e.g., California [2] and Midwest Independent System Operators [3]). Large-scale energy storage is considered as one of the potential enablers for a more flexible grid, and thus is expected to grow significantly over the coming years [4]. Also, the Federal Energy Regulatory Commission (FERC) allows energy storage, as one of so-called "non-generation" resources, to participate in electricity markets [5]. Therefore, a number of works have been reported that focus on the operation of energy storage [6]-[12].

From a broader perspective, the existing literature on the optimal operation of energy storage systems can be divided into two categories. In the first category, energy storage facilities are operated as a part of network assets in a vertically integrated power system [6]-[8]. In [6], the ramping capability of a storage system is used to manage the intra-hour net load. The work in [6] investigates the reduction in different conventional generators' ramping activity by increasing ramping capability of storage systems. In [7], it is concluded that larger storage facilities lead to less ramping constraints and thus, reduction of the total system cost. In [8], dispatching storage systems to mitigate forecast errors of wind power production is discussed considering the ramping capabilities of storage facilities. In this category of studies, energy storage is not considered as an independent for-profit entity, and thus, its profitability is not addressed.

In the second category, energy storage is operated as a merchant for-profit entity. These studies can further be divided into two groups, depending on how the storage systems impact market prices. In the first group, the storage facilities are treated as price-takers, i.e., they are assumed to be small enough such that their actions do not affect market prices. In such a context, the operation of the storage facilities is optimized under the assumption that future market prices are exogenous parameters. Hence, the storage operator would forecast the future market prices using historical data, and optimizes its operation decisions accordingly. In [9], a forprofit storage system is sized considering the impact of its ramp constraints on its economic gain.

The second group of studies focuses on large-scale storage facilities. The interest in large-scale energy storage is growing due particularly to new supporting policies [13]. For example, Alberta Innovates-Energy and Environment Solutions (AIEES) announced a two million dollar budget in 2014 to support storage facility investment in Alberta [14]. As a result of growing interest in energy storage, various large-scale storage facilities are announced worldwide [13]. For example, one large pump-hydro storage and one large compressed air energy storage systems were filed with the Alberta Electric System Operator (AESO) in 2014 [15]. Such large storage facilities could become price-makers, i.e., they are large and their operation decisions may actually impact market-clearing outcomes. Considering variability and uncertainty in Alberta's net load due to high wind power penetration, these largescale storage facilities may exert market power due to their ramping capabilities. Through their strategic decisions, the storage facilities could influence market-clearing outcomes to their benefit.

Note that ignoring the bi-directional interactions between large-scale storage facilities' decisions and the market clearing process may lead to less economical operational decisions [10]. Therefore, in line with [10]-[12], we analyze the impacts of storage operation decisions on market-clearing outcomes. In such a case where the strategic operation of storage facilities is addressed, the market prices cannot be treated as parameters, and should be endogenously obtained. In [10], the impact of energy storage operation on social welfare in an imperfect competition is studied using a Cournot model. In [11], [12], a complementarity approach is proposed to determine optimal operation of a storage system.

In line with [10]-[12], we study the pool strategy of a pricemaker storage system whose aim is to maximize its profit through inter-temporal arbitrage. However, unlike [10]-[12], we consider the ramping capability of conventional generators and introduce it as an opportunity for the storage facility to strategically adjust its pool strategies and increase its profit. The price-maker storage, whose actions could influence market outcomes and clearing prices, takes advantage of technical limitations of the rest of the supply fleet. Note that the ability of a storage facility to influence market-clearing outcomes to its own advantage depends on the tightness level of other players' technical limits; in particular, it depends on the ramp limits of conventional generators. In markets with insufficient ramping resources and a significant share of wind power production, storage facilities can potentially behave strategically.

Compared to an individual price-responsive load or a conventional generator, energy storage systems could participate in the market as a load or as a generator and switch between charging, discharging, and idle modes regularly depending on market situation. Also, the buying and selling decisions are not entirely independent; this is because the overall profit depends 
on the difference between the price of purchased electricity and the energy sold back to the market. These dependencies make a storage system's decision-making problem more complex than individual loads or generators. However, they also introduce more operation flexibility by switching between charging, discharging and idle modes.

The main contribution of this paper is to model the pool strategies of a large-scale price-maker merchant storage system considering the ramping capability of other generators in the presence of high wind power penetration into the power system. To do so, a bi-level optimization model is proposed. The objective of this model is to maximize the storage system's expected profit through its strategic discharging and charging (i.e., strategic inter-temporal arbitrage) decisions considering wind power uncertainty. The storage system needs to decide how much energy to buy or to sell at what price at any given hour over an extended operation period, say over 24 hours. The primal-dual and Karush-Kuhn-Tucker (KKT) conditions are derived from transforming the proposed bi-level problem into a Mathematical Program with Equilibrium Constraints (MPEC) that can be recast as a Mixed-integer Linear Programming (MILP) problem. The significance of the proposed model is that it makes it possible to analyze the impacts of available ramping capability in the market on the storage facility's profitability. Using the proposed model, we also investigate the impacts of supply curve shape and transmission limitations on the profitability of the storage facility. Furthermore, impacts of wind power uncertainty on the operation of the storage facility are studied.

The rest of this paper is organized as follows. The mathematical formulation of the proposed model is provided in Section III The results are presented and discussed in Section III] The paper is concluded in Section IV

\section{Methodology and Formulation}

The proposed bi-level model has two components, i.e., an upper-level problem to model the operation of the storage system and a number of lower-level problems to model the market clearing process under different wind power scenarios. Note that the upper-level objective function is constrained by the upper-level constraints as well as the lower-level problems. The upper and lower-level problems are first discussed, and then the proposed bi-level model is transformed into a singlelevel MPEC and solved accordingly.

\section{A. The Upper-Level Problem: Profit Maximization of the Price-Maker Storage System}

The upper-level problem seeks to maximize the storage system's expected profit, as formulated in a.1 a.10. The optimization variables of the upper-level problem are those in set $\Xi_{U L}=\left\{u_{s, t}^{d i s}, u_{s, t}^{c h}, u_{s, t}^{i d l}, \bar{p}_{s, t}^{d i s}, \bar{p}_{s, t}^{c h}, o_{s, t}^{d i s}, o_{s, t}^{c h}\right.$ , $\left.e_{s, t, w}\right\}$ as well as primal and dual variable sets of the lowerlevel problems, i.e., $\Xi_{L L}^{\text {Primal }}$ and $\Xi_{L L}^{\text {Dual }}$, respectively. These two sets are defined in later parts.

$\underset{\Xi_{U L}}{\operatorname{Max}}$

$$
\begin{array}{r}
\sum_{w=1}^{N_{w}} \Phi_{w} \cdot \sum_{t=1}^{N_{t}} \sum_{s:(s, i) \in Q_{s}, s=1}^{N_{s}}-\left[\left(\lambda_{i, t, w}+M C_{s}^{c h}\right) \cdot p_{s, t, w}^{c h}\right. \\
\left.+\left(\lambda_{i, t, w}-M C_{s}^{d i s}\right) \cdot p_{s, t, w}^{d i s}\right]
\end{array}
$$

S.t.

$$
\begin{aligned}
& u_{s, t}^{d i s}+u_{s, t}^{c h}+u_{s, t}^{i d l}=1 \quad \forall s, \forall t \\
& 0 \leq \bar{p}_{s, t}^{d i s} \leq u_{s, t}^{d i s} \cdot P_{s}^{d i s, \max } \forall s, \forall t \\
& 0 \leq \bar{p}_{s, t}^{c h} \leq u_{s, t}^{c h} \cdot P_{s}^{c h, \max } \forall s, \forall t \\
& o_{s, t}^{d i s} \geq 0 \quad \forall s, \forall t \\
& o_{s, t}^{c h} \geq 0 \quad \forall s, \forall t \\
& 0 \leq e_{s, t, w} \leq E_{s}^{\max } \forall s, \forall t, \forall w \\
& e_{s, t, w}=E_{s}^{i n i}-p_{s, t, w}^{d i s}+\eta_{s} \cdot p_{s, t, w}^{c h} \quad \forall s, t=1, \forall w \\
& e_{s, t, w}=e_{s,(t-1), w}-p_{s, t, w}^{d i s}+\eta_{s} \cdot p_{s, t, w}^{c h} \quad \forall s, \forall t>1, \forall w \\
& e_{s, t, w}=\alpha_{s} \cdot E_{s}^{i n i} \forall s, t=N_{t}, \forall w
\end{aligned}
$$

The objective function a.1 is composed of two terms. The first term is associated with the cost incurred for purchasing and storing energy in the charging mode. It is composed of the expected cost of buying energy from market and the costs that might be associated with storing this energy by the energy storage charging device (e.g., the costs of compression in the case of compressed air energy storage). The second term is associated with the expected profit of the energy storage in discharging mode; this is calculated through the revenue achieved by selling energy to the market minus the costs that might be associated with releasing the stored energy (e.g., the expanding costs in the case of compressed air energy storage). In this paper, we formulate the offering strategy problem for a general energy storage system. However, depending on the specific technology, further modifications may need to be included to reflect technology-specific issues related to energy storage systems. For example, for compressed air energy storage facilities, the energy conversion inefficiency and losses need to be considered, or for batteries, the depth of discharge limitations may become relevant. Note that locational marginal prices (LMPs), denoted by $\lambda_{i, t, w}$, are endogenously obtained from the lower-level problems.

Three operation modes for the energy storage system are considered in a.2, which are discharging, charging, and idling, i.e., when the storage system is operating in neither discharging nor charging modes. Constraints a.3 and a.4 bind the energy storage quantity offers and bids, respectively. Constraints a.5 and a.6 enforce the non-negativity of the energy storage price offers and bids, respectively. Constraint a.7) refers to upper and lower bounds for the storage system energy reservoir. Constraints a.8 and a.9 represent the energy storage state of charge for the first and rest of hours, respectively. Note that losses in all three operation modes are lumped into the energy storage system inefficiency. Constraint a.10) is designed to specify the state of charge at the end of the planning horizon. Generally, storage facilities are fastramping utilities. In this work, no limitations are imposed on the ramping capability of the storage facility, i.e., the facility 
can ramp up to its maximum capacity or fully shut down in a one-hour interval. Note that in the upper-level problem, the storage facility makes its strategic operation (i.e., offering and bidding) decisions in terms of quantity and price, i.e., $\bar{p}_{s, t}^{\text {dis }}$, $\bar{p}_{s, t}^{c h}, o_{s, t}^{d i s}$ and $o_{s, t}^{c h}$.

\section{B. The Lower-Level Problems: Market Clearing Process Un- der Different Wind Power Scenarios}

The lower-level problems allow the storage facility to adjust its strategic decisions made in the upper-level problem regarding different physical and financial market conditions. The wind power uncertainty is modeled in this paper using a stochastic setup [16] in which, the wind power uncertainty is represented through a number of scenarios. Thus, in the lower-level, the market operator clears the market based on submitted bids and offers for each scenario. We assume that non-storage participants submit their offer and bid prices based on their marginal cost/utility. In particular, each wind producer offers at its marginal cost, which is assumed to be zero. These assumptions enable us to model the problem of this paper as an MPEC, in line with [17]. Considering strategic behavior for all market participants is not the focus of this paper, and will be addressed in our future research.

The lower-level problem for each scenario is formulated in (b.1)-(b.14), which is a constraint for the upper-level problem:

$$
\begin{aligned}
& \left\{\begin{array}{c}
\text { Min. } \\
\Xi_{L L}^{\text {primal }}
\end{array}\right. \\
& \sum_{t=1}^{N_{t}}\left[\sum_{g=1}^{N_{g}} M C_{g} \cdot p_{g, t, w}+\sum_{s=1}^{N_{s}} o_{s, t}^{d i s} \cdot p_{s, t, w}^{d i s}\right. \\
& \left.\quad-\sum_{s=1}^{N_{s}} o_{s, t}^{c h} \cdot p_{s, t, w}^{c h}-\sum_{d=1}^{N_{d}} U_{d, t} \cdot p_{d, t, w}\right]
\end{aligned}
$$

S.t.

$$
\begin{aligned}
& \sum_{d:(d, i) \in Q_{d}, d=1}^{N_{d}} p_{d, t, w}-\sum_{s:(s, i) \in Q_{s}, s=1}^{N_{s}}\left[p_{s, t, w}^{d i s}-p_{s, t, w}^{c h}\right] \\
& -\sum_{g:(g, i) \in Q_{g}, g=1}^{N_{g}} p_{g, t, w}-\sum_{k:(k, i) \in Q_{k}, k=1}^{N_{k}} p_{k, t, w} \\
& =\sum_{j \in \Psi_{i}, j=1}^{N_{j}} B_{i, j} .\left(\delta_{j, t, w}-\delta_{i, t, w}\right): \lambda_{i, t, w} ; \forall i, \forall t \\
& 0 \leq p_{g, t, w} \leq P_{g}^{\text {max }}: \mu_{g, t, w}^{\text {min }}, \mu_{g, t, w}^{\text {max }} ; \quad \forall g, \forall t \\
& p_{g, t, w}-P_{g}^{i n i} \leq R U_{g}^{\text {max }}: \mu_{g, t, w}^{r u} ; \quad \forall g, t=1 \\
& p_{g, t, w}-p_{g,(t-1), w} \leq R U_{g}^{\text {max }}: \mu_{g, t, w}^{r u} ; \quad \forall g, \forall t>1 \\
& P_{g}^{\text {ini }}-p_{g, t, w} \leq R D_{g}^{\text {max }}: \mu_{g, t, w}^{r d} ; \forall g, t=1 \\
& p_{g,(t-1), w}-p_{g, t, w} \leq R D_{g}^{\text {max }}: \mu_{g, t, w}^{r d} ; \quad \forall g, \forall t>1 \\
& B_{i, j} \cdot\left(\delta_{i, t, w}-\delta_{j, t, w} \leq P_{i, j}^{\text {max }}: \mu_{i, j, t, w}^{p l} \quad \forall i, \forall j \in \Psi_{i}, \forall t\right. \\
& \delta^{\text {min }} \leq \delta_{i, t, w} \leq \delta^{\text {max }}: \mu_{i, t, w}^{\text {min }}, \mu_{i, t, w}^{\text {max }} ; \quad \forall i, \forall t
\end{aligned}
$$

$$
\begin{aligned}
& 0 \leq p_{k, t, w} \leq P_{k, t, w}^{f o r}: \mu_{k, t, w}^{\min }, \mu_{k, t, w}^{\max } ; \quad \forall k, \forall t \\
& 0 \leq p_{d, t, w} \leq P_{d, t}^{\max }: \mu_{d, t, w}^{\min }, \mu_{d, t, w}^{\max } ; \quad \forall d, \forall t \\
& 0 \leq p_{s, t, w}^{\text {dis }} \leq \bar{p}_{s, t}^{\text {dis }}: \mu_{s, t, w}^{\text {dis,min }}, \mu_{s, t, w}^{\text {dis,max }} ; \quad \forall s, \forall t \\
& 0 \leq p_{s, t, w}^{c h} \leq \bar{p}_{s, t}^{c h}: \mu_{s, t, w}^{c h, \min }, \mu_{s, t, w}^{c h, \max } ; \quad \forall s, \forall t \\
& \} \forall w
\end{aligned}
$$

The objective function of each lower-level problem (b.1) seeks to minimize the negative of social welfare. Social welfare is generally defined as the difference between the benefit that the produced energy brings to a society, which is evaluated by the willingness of the society to pay for it, and the total cost of producing that energy [18]. The primal and dual variables of each lower-level problem are those in the set of $\Xi_{L L}^{\text {Primal }}=$ $\left\{p_{g, t, w}, p_{k, t, w}, p_{s, t, w}^{d i s}, p_{s, t, w}^{c h}, p_{d, t, w}, \delta_{i, t, w}\right\}$ and $\Xi_{L L}^{D u a l}=$ $\left\{\lambda_{i, t, w}, \mu_{g, t, w}^{\min }, \mu_{g, t, w}^{\max }, \mu_{g, t, w}^{r u}, \mu_{g, t, w}^{r d}, \mu_{i, j, t, w}^{p l}, \mu_{i, t, w}^{\min }, \mu_{i, t, w}^{\max }\right.$, $\mu_{1, t, w}, \mu_{k, t, w}^{\min }, \mu_{k, t, w}^{\max }, \mu_{d, t, w}^{\min }, \mu_{d, t, w}^{\max }, \mu_{s, t, w}^{d i s, \max }, \mu_{s, t, w}^{d i s, \min }$, $\left.\mu_{s, t, w}^{c h, \max }, \mu_{s, t, w}^{c h, m i n}\right\}$, respectively. Note that the offering and bidding decisions of the price-maker storage system, i.e., $\bar{p}_{s, t}^{\text {dis }}$, $\bar{p}_{s, t}^{c h}, o_{s, t}^{d i s}$ and $o_{s, t}^{c h}$ are upper-level decision variables; those are treated as fixed values in the lower-level problems, i.e., in the market clearing process. This makes the lower-level problems continuous, linear, and thus convex [19]. Note that bidding, offering, and operation mode decisions of the storage facility should be adopted for all foreseen scenarios. Thus, they are scenario-independent variables, whereas other variables are scenario-dependent (indexed by $w$ ). Dual variables pertaining to the lower-level constraints are specified at each equation following a colon. Constraint b.2 represents the energy balance at each bus, whose dual variable provides the LMP at that bus. Constraint (b.3) binds generators' production level. Constraints (b.4)-(b.5) and (b.6)-(b.7) are applied to enforce the ramp up and down limits of conventional generators, respectively. Constraint (b.8) enforces the capacity limit of transmission lines. Constraint (b.9) binds nodal voltage angles, and constraint b.10) forces $i=1$ to be the reference bus. Constraint b.11 binds the wind power production to lie within zero and the forecasted value. Note that this constraint implicitly allows the excessive wind power to be spilled. Note also that the upper bound of this constraint, i.e., $P_{k, t, w}^{f o r}$, is an uncertain parameter indexed by $w$, which represents the wind power uncertainty. Constraint (b.12) binds the consumption level of load demand entities. Constraints (b.13) and (b.14) enforce the accepted discharge/charge quantities to lie within zero and the submitted quantity offer/bid, respectively.

\section{Single-Level MPEC and its Linearization}

In order to transform the bi-level model a.1 - b.14 into a single-level MPEC, the primal-dual transformation is applied to each lower-level problem (b.1)- b.14) to derive their optimality conditions. Accordingly, c.1)-(c.13) provide the dual constraints associated with each lower-level problem (b.1)(b.14). In addition, c.14) refers to the strong duality condition corresponding to each lower-level problem; this enforces the 
equality of its primal and dual objective function values at the optimal solution.

$\left\{o_{s, t}^{d i s}-\lambda_{i:(i, s) \in Q_{s, i}, t, w}+\mu_{s, t, w}^{d i s, \max }-\mu_{s, t, w}^{d i s, \min }=0 \quad \forall s, \forall t\right.$

$-o_{s, t}^{c h}+\lambda_{i:(i, s) \in Q_{s, i}, t, w}+\mu_{s, t, w}^{c h, \max }-\mu_{s, t, w}^{c h, \min }=0 \quad \forall s, \forall t$

$M C_{g}-\lambda_{i:(i, g) \in Q_{g, i}, t, w}+\mu_{g, t, w}^{\max }-\mu_{g, t, w}^{\min }+\mu_{g, t, w}^{r u}$

$-\mu_{g,(t+1), w}^{r u}-\mu_{g, t, w}^{r d}+\mu_{g,(t+1), w}^{r d}=0 \quad \forall g, \forall t<N_{t}$

$M C_{g}-\lambda_{i:(i, g) \in Q_{g, i}, t, w}+\mu_{g, t, w}^{\max }-\mu_{g, t, w}^{\min }+\mu_{g, t, w}^{r u}$

$-\mu_{g, t, w}^{r d}=0 \quad \forall g, t=N_{t}$

$-U_{d, t}+\lambda_{i:(i, d) \in Q_{d, i}, t, w}+\mu_{d, t, w}^{\max }-\mu_{d, t, w}^{\min }=0 \quad \forall d, \forall t$

$-\lambda_{i:(i, k) \in Q_{k, i}, t, w}+\mu_{k, t, w}^{\max }-\mu_{k, t, w}^{\min }=0 \quad \forall k, \forall t$

$\sum_{j \in \Psi_{i}, j=1}^{N_{j}} B_{i, j} \cdot\left(\lambda_{i, t, w}-\lambda_{j, t, w}\right)+\sum_{j \in \Psi_{i}, j=1}^{N_{j}} B_{i, j} \cdot\left(\mu_{i, j, t, w}^{p l}\right.$

$\left.-\mu_{j, i, t, w}^{p l}\right)+\mu_{i, t, w}^{\max }-\mu_{i, t, w}^{\min }+\left(\mu_{1, t, w}\right)_{i=1}=0 \quad \forall i, \forall t$ (c.7)

$\mu_{g, t, w}^{\max }, \mu_{g, t, w}^{\min }, \mu_{g, t, w}^{r u}, \mu_{g, t, w}^{r d} \geq 0 \quad \forall g, \forall t$

$\mu_{i, j, t, w}^{p l} \geq 0 \quad \forall i, \forall j \in \Psi_{i}, \forall t$

$\mu_{i, t, w}^{\max }, \mu_{i, t, w}^{\min } \geq 0 \quad \forall i, \forall t$

$\mu_{d, t, w}^{\max }, \mu_{d, t, w}^{\min } \geq 0 \quad \forall d, \forall t$

$\mu_{k, t, w}^{\max }, \mu_{k, t, w}^{\min } \geq 0 \quad \forall k, \forall t$

$\mu_{s, t, w}^{d i s, \max }, \mu_{s, t, w}^{d i s, \min }, \mu_{s, t, w}^{c h, \max }, \mu_{s, t, w}^{c h, \text { min }} \geq 0 \quad \forall s, \forall t$

$\sum_{t=1}^{N_{t}}\left[\sum_{g=1}^{N_{g}} M C_{g} \cdot p_{g, t, w}+\sum_{s=1}^{N_{s}} o_{s, t}^{d i s} \cdot p_{s, t, w}^{d i s}\right.$

$\left.-\sum_{s=1}^{N_{s}} o_{s, t}^{c h} \cdot p_{s, t, w}^{c h}-\sum_{d=1}^{N_{d}} U_{d, t} \cdot p_{d, t, w}\right]=$

$-\sum_{t=1}^{N_{t}} \sum_{s=1}^{N_{s}}\left[\mu_{s, t, w}^{d i s, \max } \cdot \bar{p}_{s, t}^{d i s}+\mu_{s, t, w}^{c h, \max } \cdot \bar{p}_{s, t}^{c h}\right]+X_{w}$

where,

$X_{w}=$

$-\sum_{t=1}^{N_{t}} \sum_{g=1}^{N_{g}}\left[\mu_{g, t, w}^{\max } \cdot P_{g}^{\max }+\mu_{g, t, w}^{r u} \cdot R U_{g}^{\max }+\mu_{g, t, w}^{r d} \cdot R D_{g}^{\max }\right]$

$+\sum_{g=1}^{N_{g}}\left[\mu_{g,(t=1), w}^{r u} \cdot P_{g}^{i n i}-\mu_{g,(t=1), w}^{r d} \cdot P_{g}^{i n i}\right]$

$-\sum_{t=1}^{N_{t}} \sum_{k=1}^{N_{k}}\left[\mu_{k, t, w}^{\max } . P_{k, t, w}^{f o r}\right]-\sum_{t=1}^{N_{t}} \sum_{d=1}^{N_{d}}\left[\mu_{d, t, w}^{\max } \cdot P_{d, t}^{\max }\right]$

$-\sum_{t=1}^{N_{t}} \sum_{i=1}^{N_{i}} \sum_{j \in \Psi_{i}, j=1}^{N_{j}}\left[\mu_{i, j, t, w}^{p l} \cdot P L_{i, j}^{\max }\right]$
$-\sum_{t=1}^{N_{t}} \sum_{i=1}^{N_{i}}\left[\mu_{i, t, w}^{\max } . \delta^{\max }-\mu_{i, t, w}^{\min } . \delta^{\min }\right]$

\}$\forall w$

Since the storage facility works at both discharging and charging modes, it submits bids as well as offers, which are addressed in (c.1) and (c.2), respectively. Thus, bid and offer prices are interconnected, while conventional generators only submit offers into the market. Besides, the dual variables associated with the ramp constraints of conventional generators are included in (c.3) and (c.4); those reflect the impacts of the generators' ramp up and down limits on LMPs and in turn, the storage facility's pool strategies.

The single-level MPEC includes the upper-level problem (a.1)-(a.10), the lower-level problems' primal constraints (b.2)(b.14), the lower-level problems' dual constraints c.1 - c.13 and the strong duality condition (c.14). However, this MPEC is non-linear due to the product of prices and quantities in (c.14) and a.1. Pursuing linearity, the strong duality condition can be replaced by the set of complementarity conditions obtained from the KKT conditions associated with the lowerlevel problems [20]. Each complementarity condition can be linearized by its mixed-integer linear equivalent through the Big-M approach proposed in [21]. The selection of Big-M values can be challenging since relatively small values may result in increased computational burden whereas relatively big values may lead to numerical ill-conditioning. To handle this concern, we first arbitrarily select big values, and then solve the model. Next, we check the numerical results to validate if each complementarity condition holds. If not, the corresponding Big-M value is reduced, and then the model is resolved. This tuning-up process continues until all complementarity conditions hold.

Finally, the linear equivalent expression of the objective function a.1 can be driven from the dual conditions (c.1)(c.2), the strong duality condition (c.14), and the complementarity conditions related to the storage facility's bids and offers quantities [22]. The linear objective function that is to be substituted by a.1 is stated as follows:

$$
\begin{aligned}
\underset{\Xi_{U L}}{\operatorname{Max}} & \sum_{w=1}^{N_{w}} \Phi_{w} \cdot\left\{-\sum_{t=1}^{N_{t}} \sum_{s=1}^{N_{s}}\left[M C_{s}^{d i s} \cdot p_{s, t, w}^{d i s}+M C_{s}^{c h} \cdot p_{s, t, w}^{c h}\right]\right. \\
- & \left.\sum_{t=1}^{N_{t}} \sum_{g=1}^{N_{g}} M C_{g} \cdot p_{g, t, w}+\sum_{t=1}^{N_{t}} \sum_{d=1}^{N_{d}} U_{d, t} \cdot p_{d, t, w}+X_{w}\right\}
\end{aligned}
$$

Note that in the linearized objective function (c.16), the $X_{w}$ element connects the storage facility's decision to the ramping limits of conventional units.

Similar complementarity models have been recently applied to different strategic decision-making problems within electricity markets [17], [19], [23], [24]. This approach for electricity market modeling was initially used in the pioneering work [17]. Other studies used similar models for different purposes such as strategic bidding of a large consumer in [19], strategic offering of a conventional generator in [23], 
TABLE I

CONVENTIONAL GENERATORS CHARACTERISTICS

\begin{tabular}{ccccccc}
\hline Generator No. & Bus No. & $\begin{array}{c}P_{g}^{\max } \\
(\mathrm{MW})\end{array}$ & $\begin{array}{c}M C_{g} \\
(\$ / \mathrm{MWh})\end{array}$ & $\begin{array}{c}R U_{g}^{\max } \\
(\mathrm{MW} / \mathrm{h})\end{array}$ & $\begin{array}{c}R D_{g}^{\max } \\
(\mathrm{MW} / \mathrm{h})\end{array}$ & $\begin{array}{c}P_{g}^{\text {ini }} \\
(\mathrm{MW})\end{array}$ \\
\hline G1 & 1 & 100 & 12 & 5 & 5 & 100 \\
G2 & 2 & 75 & 20 & 8 & 8 & 75 \\
G3 & 6 & 50 & 50 & 10 & 10 & 0 \\
G4 & 6 & 50 & 100 & 20 & 20 & 0 \\
\hline
\end{tabular}

TABLE II

STORAGE SYSTEM CHARACTERISTICS

\begin{tabular}{cccccc}
\hline $\begin{array}{c}\text { Storage } \\
\text { system }\end{array}$ & Bus No. & $\begin{array}{c}P_{s}^{\text {dis, } \max } \\
(\mathrm{MW})\end{array}$ & $\begin{array}{c}P_{s}^{\text {ch, } \max } \\
(\mathrm{MW})\end{array}$ & $\begin{array}{c}M C_{s}^{\text {dis }} \\
(\$ / \mathrm{MWh})\end{array}$ & $\begin{array}{c}M C_{s}^{c h} \\
(\$ / \mathrm{MWh})\end{array}$ \\
\hline 1 & 5 & 40 & 30 & 18 & 1 \\
\hline
\end{tabular}

and strategic generation investment in [24]. Recently, complementarity modeling was applied to the strategic bidding of an energy storage facility considering energy arbitrage in [11], [12]. Compared to the work in [11], [12], we build our model considering the ramping capability of conventional generators. Adding ramps introduced additional inter-temporal dependencies in the formulation, i.e., (b.4)-(b.7) compared to when ramping limits are not enforced. Because of these constraints, LMPs would become dependent upon ramping capabilities in the market as reflected in c.3)-(c.4). Thus, storage facilities bidding strategies, the market prices and economic performance of conventional generators, as well as that of the storage facility, would be affected. We also model wind power uncertainty and analyze its impacts on the profitability of the storage facility.

\section{NUMERICAL RESULTS}

Two case studies are considered in this paper, i.e., a sixbus illustrative example and the IEEE one-area reliability test system. For simplicity, and to make the findings more intuitive, we exclude wind production within the first case study, i.e., the six-bus illustrative example, and therefore, we use a deterministic setup. This way, we investigate how the technical limits of the system (e.g., ramping limits of the conventional generators and transmission capacity limits), as well as variations in the hourly loads, impact the strategic storage decisions. In the second case study, we consider wind power production, which needs a stochastic analysis. Then, we investigate how wind power uncertainty affects the strategic storage decisions.

We solved the MILP form of the proposed model using CPLEX solver under General Algebraic Modeling System (GAMS) [25]. The model was solved in all cases taking less than five minutes on a standard desktop computer.

\section{A. A Six-Bus Illustrative Example}

In this section, a six-bus system [26] is used to demonstrate the performance of the proposed methodology. In particular, the impacts of the total ramp up/down capability of the conventional generators, the smoothness level of the supply curve, i.e., the shape of the supply curve, and the transmission capacity limits on market prices and the storage facility's profit are analyzed.

Technical characteristics of the conventional generators are given in Table I] The capacity of each transmission line is considered to be $150 \mathrm{MW}$, except for line 4, which connects

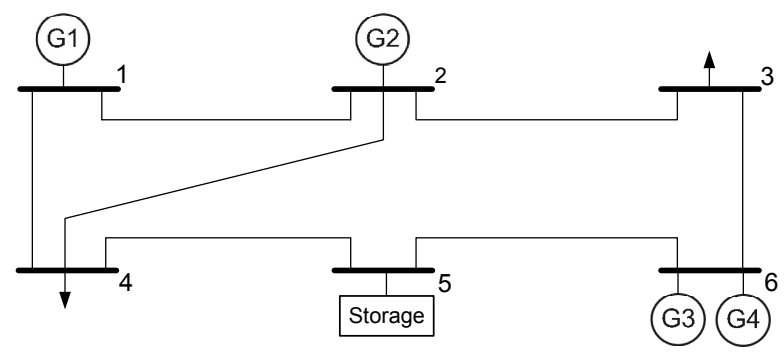

Fig. 1. A six-bus illustrative example one-line diagram

bus 2 to bus 4 , and is limited to $33 \mathrm{MW}$. The energy storage system is located at bus 5 , as presented in Fig. 1 and its technical characteristics are provided in Table II] The energy storage facility's charging and discharging components are modeled separately. This is mainly inspired by the operation of a compressed air energy storage system [27]. This separation provides further flexibility in modeling and analysis of different storage technologies. The capacity of storage system's energy reservoir is $100 \mathrm{MWh}$.

In this illustrative example, a time horizon of 24 hours is considered. This operation horizon is selected to reasonably match the storage reservoir size [28]; larger reservoirs may require a longer operation period. It is assumed that the storage system starts empty and comes back to the same state at the end of time horizon- the initial state of the charge could be any value. Also, without losing generality, the efficiency of the storage facility is assumed to be $100 \%$. The hourly load distribution over the 24 hours horizon is given in the second column of Table III. The load is distributed equally among buses 3 and 4 . The load bids at \$450/MWh for all hours.

The following test cases are studied:

- Base Case: The energy storage system does not play strategically.

- Case 1: The energy storage system is a price-maker entity, i.e., it bids and offers strategically.

- Case 2: Ramp rate limits of conventional generators are added to Case 1.

- Case 3: Transmission line capacity limits are added to Case 2.

Base Case: In this case, we assume the storage system participates in the market as a non-strategic player, and thus, the market is perfectly competitive. In this case, the generators' ramp rate limits are not considered, neither are the network constraints. The detailed numerical results for this case are presented in Table III The purpose of this case is to demonstrate a simple case where the numerical results could be tracked. Also, we will compare the results of other cases to those of this base case. Note that only the lower-level problem, i.e., the market clearing, is solved in this case since it refers to a perfectly competitive market.

In the first hour, the load is $176 \mathrm{MW}$ and is supplied by generators G1, G2, and G3. Since generators G1 and G2 are dispatched at their full capacity in this hour, the marginal cost of generator G3 sets the system marginal cost (SMC), which is $\$ 50 / \mathrm{MWh}$. In the second hour, the load is $165 \mathrm{MW}$ and the storage system is charged at a $10 \mathrm{MW}$ rate. The SMC is cleared at $\$ 31 / \mathrm{MWh}$, which is less than the marginal cost 
TABLE III

MARKET ClEARING RESUlTS IN BASE CASE: THE ENERGY STORAGE IS A NON-STRATEGIC PLAYER

\begin{tabular}{|c|c|c|c|c|c|c|c|}
\hline \multirow[b]{2}{*}{ Hour } & \multirow[b]{2}{*}{$\begin{array}{c}p_{d, t} \\
(\mathrm{MW})\end{array}$} & \multirow{2}{*}{$\begin{array}{c}p_{s, t}^{d i s} / p_{s, t}^{c h} \\
(\mathrm{MW})^{*}\end{array}$} & \multicolumn{4}{|c|}{$p_{g, t}$} & \multirow{2}{*}{$\begin{array}{c}\lambda_{i, t} \\
(\$ / \mathrm{MWh})\end{array}$} \\
\hline & & & \multicolumn{4}{|c|}{ (MW) } & \\
\hline 1 & 176 & & 100 & 75 & 1 & 0 & 50 \\
\hline 2 & 165 & -10 & 100 & 75 & 0 & 0 & 31 \\
\hline 3 & 158 & -17 & 100 & 75 & 0 & 0 & 31 \\
\hline 4 & 154 & -21 & 100 & 75 & 0 & 0 & 31 \\
\hline 5 & 155 & -20 & 100 & 70 & 0 & 0 & 31 \\
\hline 6 & 159 & -16 & 100 & 75 & 0 & 0 & 31 \\
\hline 7 & 173 & -2 & 100 & 75 & 0 & 0 & 31 \\
\hline 8 & 177 & & 100 & 75 & 2 & 0 & 50 \\
\hline 9 & 177 & & 100 & 75 & 2 & 0 & 50 \\
\hline 10 & 181 & & 100 & 75 & 6 & 0 & 50 \\
\hline 11 & 188 & & 100 & 75 & 13 & 0 & 50 \\
\hline 12 & 190 & & 100 & 75 & 15 & 0 & 50 \\
\hline 13 & 195 & & 100 & 75 & 20 & 0 & 50 \\
\hline 14 & 196 & & 100 & 75 & 21 & 0 & 50 \\
\hline 15 & 197 & & 100 & 75 & 22 & 0 & 50 \\
\hline 16 & 218 & & 100 & 75 & 43 & 0 & 50 \\
\hline 17 & 249 & 28 & 100 & 75 & 46 & 0 & 50 \\
\hline 18 & 252 & 27 & 100 & 75 & 50 & 0 & 50 \\
\hline 19 & 244 & 19 & 100 & 75 & 50 & 0 & 50 \\
\hline 20 & 237 & 12 & 100 & 75 & 50 & 0 & 50 \\
\hline 21 & 220 & & 100 & 75 & 45 & 0 & 50 \\
\hline 22 & 199 & & 100 & 75 & 24 & 0 & 50 \\
\hline 23 & 196 & & 100 & 75 & 21 & 0 & 50 \\
\hline 24 & 195 & & 100 & 75 & 20 & 0 & 50 \\
\hline
\end{tabular}

*A negative/positive value corresponds to the storage system's charging/discharging mode.

of the generator who can supply the next MW demand, i.e., generator G3. To justify this value, observe that in this hour, the next MW could be supplied by generator G2 if the storage system was being charged one less MW. The value of this MW is equal to the selling price when discharging, i.e., $\$ 50 / \mathrm{MWh}$ at either of hours, minus the storage system's operation costs in charging and discharging modes, i.e., $18+1=19 \$ / \mathrm{MWh}$. Thus, the SMC of the second hour is calculated 50-19=31 $\$ / M W h$. Similar to hour 2 , the SMC at hours 3 to 7 is $\$ 31 / \mathrm{MWh}$. For the rest of hours, the SMC is $\$ 50 / \mathrm{MWh}$, which is equal to the marginal cost of generator G3. Note that if the storage system were not operating during hours 17 to 20 , the demand would have been met by generator G4, and the SMC would have been $\$ 100 / \mathrm{MWh}$ at these four hours. However, since the storage system injects energy to the system during these hours, the SMC remains at the marginal cost of generator G3, i.e., $\$ 50 / \mathrm{MWh}$. Thus, the operation of the storage system has reduced the market price for these hours. For the remaining hours, i.e., hours 21 to 24 , generator G3 sets the price at $\$ 50 / \mathrm{MWh}$. The profit of the storage facility in this non-strategic case is zero while it is $\$ 125,250$ for the rest of the fleet.

Case 1: The market outcomes for this case are presented in Table IV. Note that the ramp rate of generators and the transmission line capacity limits are not yet enforced.

The results obtained for hour 1 are identical to those of Base Case. For hour 2, the storage system strategically bids to buy $10 \mathrm{MW}$ at $\$ 20 / \mathrm{MWh}$, which is identical to the marginal cost of generator G2. The storage system bids such that there is no need to dispatch generator G3. Thus, the demand is supplied by generators G1 and G2. The SMC for this hour is identical to the marginal cost of the last generator dispatched and the bid price of the last demand supplied, i.e., the storage facility, which is $\$ 20 / \mathrm{MWh}$. For hours 3 to 7 , the storage system's price bid is the same as hour 2 . The storage system stays in
TABLE IV

MARKET CLEARING RESULTS IN CASE 1: THE STORAGE SYSTEM PLAYS STRATEGICALLY

\begin{tabular}{|c|c|c|c|c|c|c|c|c|}
\hline \multirow[b]{2}{*}{ Hour } & \multirow[b]{2}{*}{$\begin{array}{c}p_{d, t} \\
(\mathrm{MW})\end{array}$} & \multicolumn{2}{|c|}{ Storage system } & \multicolumn{4}{|c|}{$p_{g, t}$} & \multirow[b]{2}{*}{$\begin{array}{c}\lambda_{i, t} \\
(\$ / \mathrm{MWh})\end{array}$} \\
\hline & & $\begin{array}{l}p_{s, t}^{d i s} / p_{s, t}^{c h} \\
\text { (MW) }\end{array}$ & $\begin{array}{l}o_{s, t}^{d i s} / o_{s, t}^{c h} \\
(\$ / \mathrm{MWh})\end{array}$ & $\mathrm{G}_{1}$ & & $\mathrm{G}_{3}$ & $\mathrm{G}_{4}$ & \\
\hline 1 & 176 & & & 100 & 75 & 1 & 0 & 50 \\
\hline 2 & 165 & -10 & 20 & 100 & 75 & 0 & 0 & 20 \\
\hline 3 & 158 & -17 & 20 & 100 & 75 & 0 & 0 & 20 \\
\hline 4 & 154 & -21 & 20 & 100 & 75 & 0 & 0 & 20 \\
\hline 5 & 155 & -20 & 20 & 100 & 75 & 0 & 0 & 20 \\
\hline 6 & 159 & -16 & 20 & 100 & 75 & 0 & 0 & 20 \\
\hline 7 & 173 & -2 & 20 & 100 & 75 & 0 & 0 & 20 \\
\hline 8 & 177 & & & 100 & 75 & 2 & 0 & 50 \\
\hline 9 & 177 & & & 100 & 75 & 2 & 0 & 50 \\
\hline 10 & 181 & 4 & 50 & 100 & 75 & 2 & 0 & 50 \\
\hline 11 & 188 & & & 100 & 75 & 13 & 0 & 50 \\
\hline 12 & 190 & & & 100 & 75 & 15 & 0 & 50 \\
\hline 13 & 195 & & & 100 & 75 & 20 & 0 & 50 \\
\hline 14 & 196 & & & 100 & 75 & 21 & 0 & 50 \\
\hline 15 & 197 & & & 100 & 75 & 22 & 0 & 50 \\
\hline 16 & 218 & & & 100 & 75 & 43 & 0 & 50 \\
\hline 17 & 249 & 24 & 100 & 100 & 75 & 50 & 0 & 100 \\
\hline 18 & 252 & 27 & 100 & 100 & 75 & 50 & 0 & 100 \\
\hline 19 & 244 & 19 & 100 & 100 & 75 & 50 & 0 & 100 \\
\hline 20 & 237 & 12 & 100 & 100 & 75 & 50 & 0 & 100 \\
\hline 21 & 220 & & & 100 & 75 & 45 & 0 & 50 \\
\hline 22 & 199 & & & 100 & 75 & 24 & 0 & 50 \\
\hline 23 & 196 & & & 100 & 75 & 21 & 0 & 50 \\
\hline 24 & 195 & & & 100 & 75 & 20 & 0 & 50 \\
\hline
\end{tabular}

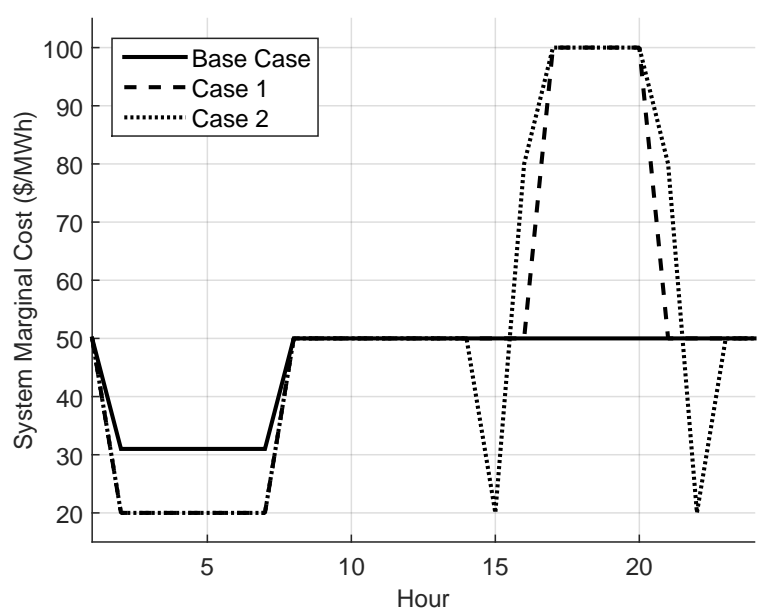

Fig. 2. Hourly SMCs in Base Case (considering a non-strategic storage), Case 1 (considering a strategic storage), and Case 2 (considering ramp rate of conventional generators)

the idle mode during hours 8,9 and 11 to 16 , but discharges 4 MW at hour 10. For hour 17 to 20, it strategically offers at a price identical to the marginal cost of generator G4. Through this strategy, generator G3 is dispatched to its maximum level, and the next MW should be supplied by generator G4. This way, the marginal cost of generator G4, i.e., $\$ 100 / \mathrm{MWh}$, sets the SMC.

The hourly SMCs for the Base Case, Case 1 and Case 2 are compared in Fig. 2. This figure shows how the strategic behavior of the storage system impacts the hourly SMCs, i.e., lower SMCs when it charges and higher SMCs when it discharges. Overall, and among all the generators, the peaking ones experience the highest increase in their profits as they only generate during the higher price hours. The storage system's profit for this case is $\$ 5,046$, which is significantly higher than that when it behaves in a non-strategic manner (Base Case).

Case 2: Ramp rate limits of the conventional generators are considered in this case, and the strategic offers/bids of 
the storage system and the market clearing outcomes are shown in Table $\mathrm{V}$. In this case, the storage facility behaves strategically and benefits from the limited ramping capability of conventional generators.

During hours 1 to 7 , the storage system plays the same as in Case 1. For hours 15 and 16, the storage system behaves such that it can take advantage of the ramp rate limits of conventional generators. The storage system strategically bids to buy $8 \mathrm{MW}$ and to sell $3 \mathrm{MW}$ at hours 15 and 16, respectively. Through this strategy, generator G3 increases its production at hour 16 , compared to hour 15 , by its maximum ramp-up rate. At the same time, generator G2 produces at its maximum level during both hours 15 and 16. At hour 16, the most economical source to supply the next MW is generator G3. However, generator G3 is reached its maximum rampup limit. Hence, generator G3 should produce one more MW during hour 15 to be able to supply the next MW during hour 16. Thus, the SMC for hour 16 is the summation of the marginal cost of generator G3 and the cost of producing one more MW by generator G3 during hour 15 . Note that for hour 15 , the cost of producing one more MW by generator G3 and reducing one MW generation of generator $\mathrm{G} 2$ is equal to the difference between the marginal cost of generators G2 and G3; this is, in fact, the value obtained for the dual variable associated with the ramp-up constraint of generator $\mathrm{G} 3$, and is equal to $\$ 30 / \mathrm{MWh}$. Thus, the SMC is $\$ 80 / \mathrm{MWh}$ for hour 16. For hour 15, the SMC is $\$ 20 / \mathrm{MWh}$, which implies that if generator $\mathrm{G} 3$ produces one more $\mathrm{MW}$, the SMC would decrease by $\$ 30 / \mathrm{MWh}$ in the next hour. Hence, the value of supplying each $\mathrm{MW}$ is $50-30=20 \$ / \mathrm{MWh}$ for hour 15. Similarly, at other hours, the storage system adjusts its operation strategies according to the ramp rate limitations of other generators, which leads to increasing its profit to $\$ 5,440$; this is comparatively higher than that in Case 1.

As illustrated in Fig. 2, the strategic storage further influences the hourly SMCs in Case 2 to its own advantage compared to that in Base Case and Case 1. Strategic storage operation considering ramp rate limits of generators also benefits peak generators at the expense of load consumers. Since the storage systems strategies force the peak generators to reach their maximum ramp rates, they gain the most increased profit among generators in this case. For example, the strategic decisions of the storage facility lead to the increased profit of generator G3 at hours 15 and 16, compared to Case 1, whereas generators $\mathrm{G} 1$ and $\mathrm{G} 2$ earn the same profits as Case 1 during these two hours.

Case 3: Transmission capacity limits are enforced in this case to highlight their impacts on pool strategy of the storage system. Depending on which line is congested, the storage system may gain or lose profit. The capacity of the transmission line connected bus 2 to bus 4 is chosen to be low to underline the importance of transmission line capacity limits on the storage system's bidding strategies. The LMPs and marketclearing outcomes for Case 3 are presented in Fig. 3 and Table VI respectively. The LMPs for all buses in Case 3 shown in Fig. 3 follows the same pattern as Case 2, Fig. 2. When the network is not congested, the market prices for all buses are equal at the exact same values as Case 2. On the other hand, in
TABLE V

MARKET CLEARING RESULTS IN CASE 2: CONSIDERING RAMP RATE LIMITS OF GENERATORS

\begin{tabular}{|c|c|c|c|c|c|c|c|c|}
\hline \multirow{2}{*}{ Hour } & \multirow[b]{2}{*}{$\begin{array}{c}p_{d, t} \\
(\mathrm{MW})\end{array}$} & \multicolumn{2}{|c|}{ Storage system } & \multicolumn{4}{|c|}{$p_{g, t}$} & \multirow[b]{2}{*}{$\begin{array}{c}\lambda_{i, t} \\
(\$ / \mathrm{MWh})\end{array}$} \\
\hline & & $\begin{array}{l}p_{s, t}^{d i s} / p_{s, t}^{c h} \\
\text { (MW) }\end{array}$ & $\begin{array}{c}o_{s, t}^{d i s} / o_{s, t}^{c h} \\
(\$ / \mathrm{MWh}\end{array}$ & $\mathrm{G}_{1}$ & $\mathrm{G}_{2}$ & $\mathrm{G}_{3}$ & $\mathrm{G}_{4}$ & \\
\hline 1 & 176 & & & 100 & 75 & 1 & 0 & 50 \\
\hline 2 & 165 & -10 & 20 & 100 & 75 & 0 & 0 & 20 \\
\hline 3 & 158 & -17 & 20 & 100 & 75 & 0 & 0 & 20 \\
\hline 4 & 154 & -21 & 20 & 100 & 75 & 0 & 0 & 20 \\
\hline 5 & 155 & -20 & 20 & 100 & 75 & 0 & 0 & 20 \\
\hline 6 & 159 & -16 & 20 & 100 & 75 & 0 & 0 & 20 \\
\hline 7 & 173 & -2 & 20 & 100 & 75 & 0 & 0 & 20 \\
\hline 8 & 177 & 2 & 50 & 100 & 75 & 0 & 0 & 50 \\
\hline 9 & 177 & & & 100 & 75 & 2 & 0 & 50 \\
\hline 10 & 181 & & & 100 & 75 & 6 & 0 & 50 \\
\hline 11 & 188 & & & 100 & 75 & 13 & 0 & 50 \\
\hline 12 & 190 & & & 100 & 75 & 15 & 0 & 50 \\
\hline 13 & 195 & & & 100 & 75 & 20 & 0 & 50 \\
\hline 14 & 196 & & & 100 & 75 & 21 & 0 & 50 \\
\hline 15 & 197 & -8 & 20 & 100 & 75 & 30 & 0 & 20 \\
\hline 16 & 218 & 3 & 80 & 100 & 75 & 40 & 0 & 80 \\
\hline 17 & 249 & 24 & 100 & 100 & 75 & 50 & 0 & 100 \\
\hline 18 & 252 & 27 & 100 & 100 & 75 & 50 & 0 & 100 \\
\hline 19 & 244 & 19 & 100 & 100 & 75 & 50 & 0 & 100 \\
\hline 20 & 237 & 12 & 100 & 100 & 75 & 50 & 0 & 100 \\
\hline 21 & 220 & 5 & 80 & 100 & 75 & 40 & 0 & 80 \\
\hline 22 & 199 & -6 & 20 & 100 & 75 & 30 & 0 & 20 \\
\hline 23 & 196 & & & 100 & 75 & 21 & 0 & 50 \\
\hline 24 & 195 & 8 & 50 & 100 & 74 & 12 & 0 & 50 \\
\hline
\end{tabular}

the congested hours, the market prices are different with Case 2. Pursuing higher market-clearing prices in the peak hours, the storage facility strategically offers its energy injection at comparatively low prices to be discharged at pre-peak hours. This way, generator $\mathrm{G} 3$ reaches its maximum ramp limits at hour 17 and thereby market prices experience the highest value at this hour, which is even more than that of the peak hour, i.e., hour 18. In this case, the transmission system is congested during the peak hours. For example, Fig. 4 shows line flows and LMP values for hour 17. Observe that the flow across the congested line hits the maximum capacity during this hour. The storage system adjusts its strategy to take advantage of the congested system. The storage system is paid based on LMP of bus 5, which is the cost of supplying the next MW at this bus. One MW demand at bus 5 can be supplied if one MW is reduced from the load demand at bus 4 , which costs $\$ 450$. On the other hand, since one MW is reduced from load demand at bus 4, generator G2 can use this extra capacity to supply the load at bus 3 . Thus, the value of supplying the next MW at bus 5 is $381.423(450-88.577+20) \$ / M W h$. In the congested network, the storage system cannot discharge as much as the previous case. However, it increases its offer prices, leading to higher prices and thus a higher profit, i.e., $\$ 18,157$.

To further highlight the impacts of physical market conditions on storage system's profitability, we investigate how the total ramp up/down capability of conventional generators affects the storage system's profitability, which is depicted in Fig. 5 The storage system gains more profit in the case of inflexible generation-side with very limited ramping capability. However, its profit decreases as generation-side becomes more flexible. This concludes that the storage system makes more business in case of inflexible systems, as expected.

In addition, the impact of a generator's submitted offers on the storage systems profit is shown in Fig. 6 To this end, the price offer of the most expensive conventional generator (i.e., 
TABLE VI

MARKET CLEARING RESULTS IN CASE 3: CONSIDERING RAMP RATE LIMITS OF GENERATORS AND TRANSMISSION CAPACITY LIMITS

\begin{tabular}{|c|c|c|c|c|c|c|c|}
\hline \multirow{2}{*}{ Hour } & \multirow{2}{*}{$\begin{array}{c}\sum_{d=1}^{N_{d}} p_{d, t} \\
(\mathrm{MW})\end{array}$} & \multicolumn{2}{|c|}{ Storage system } & \multicolumn{4}{|c|}{$p_{g, t}$} \\
\hline & & $\begin{array}{l}p_{s, t}^{d i s} / p_{s, t}^{c h} \\
\text { (MW) }\end{array}$ & $\begin{array}{l}o_{s, t}^{d i s} / o_{s, t}^{c h} \\
\text { (\$/MWh) }\end{array}$ & $\mathrm{G}_{1}$ & $\mathrm{G}_{2}$ & $\begin{array}{l}\mathrm{G}_{3} \\
\mathrm{~W})\end{array}$ & $\mathrm{G}_{4}$ \\
\hline 1 & 176 & & & 100 & 75 & 1 & 0 \\
\hline 2 & 165 & -10 & 20 & 100 & 75 & 0 & 0 \\
\hline 3 & 158 & -17 & 20 & 100 & 75 & 0 & 0 \\
\hline 4 & 154 & -21 & 20 & 100 & 75 & 0 & 0 \\
\hline 5 & 155 & -20 & 20 & 100 & 75 & 0 & 0 \\
\hline 6 & 159 & -16 & 20 & 100 & 75 & 0 & 0 \\
\hline 7 & 173 & -2 & 20 & 100 & 75 & 0 & 0 \\
\hline 8 & 177 & & & 100 & 75 & 2 & 0 \\
\hline 9 & 177 & & & 100 & 75 & 2 & 0 \\
\hline 10 & 181 & & & 100 & 75 & 6 & 0 \\
\hline 11 & 188 & & & 100 & 75 & 13 & 0 \\
\hline 12 & 190 & & & 100 & 75 & 15 & 0 \\
\hline 13 & 195 & & & 100 & 75 & 20 & 0 \\
\hline 14 & 196 & 9.595 & 20 & 100 & 75 & 11.405 & 0 \\
\hline 15 & 197 & 0.595 & 20 & 100 & 75 & 21.405 & 0 \\
\hline 16 & 218 & 11.595 & 38.061 & 100 & 75 & 31.405 & 0 \\
\hline 17 & 249 & 16.499 & 381.423 & 100 & 71.096 & 41.405 & 20 \\
\hline 18 & 252 & 19.737 & 303.638 & 100 & 75 & 50 & 7.263 \\
\hline 19 & 244 & 15.194 & 303.638 & 100 & 75 & 50 & 3.806 \\
\hline 20 & 237 & 11.219 & 303.638 & 100 & 75 & 50 & 0.781 \\
\hline 21 & 220 & 1.566 & 303.638 & 100 & 75 & 41.667 & 1.768 \\
\hline 22 & 199 & -7.667 & 20 & 100 & 75 & 31.667 & 0 \\
\hline 23 & 196 & -0.667 & 30 & 100 & 75 & 21.667 & 0 \\
\hline 24 & 195 & 8.333 & 50 & 100 & 75 & 11.667 & 0 \\
\hline
\end{tabular}

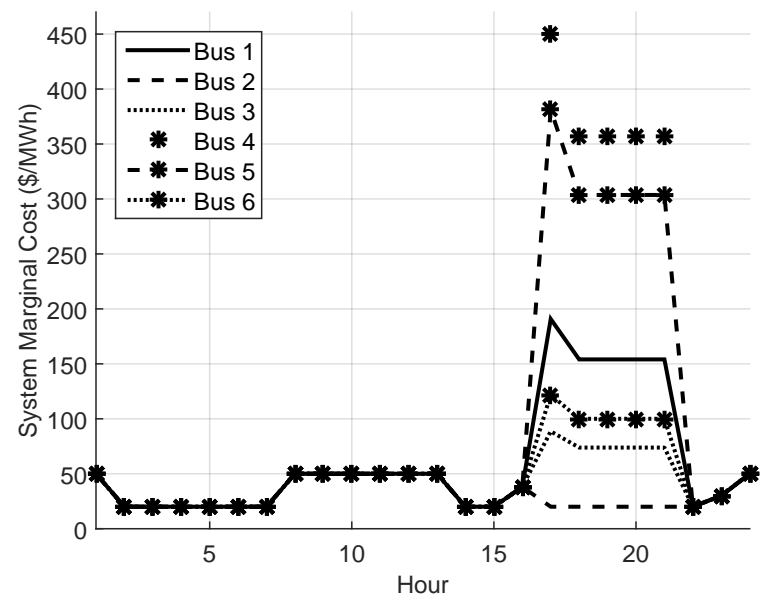

Fig. 3. Hourly SMCs in Case 3

generator G4) is changed from $\$ 50 / \mathrm{MWh}$, which is equal to the price offer of generator G3, to $\$ 130 / \mathrm{MWh}$. A lower price offer corresponds to a smooth supply curve while a higher price offer makes the supply curve non-smooth. According to Fig. 6, the storage system makes more money in case of a non-smooth supply stack.

\section{B. The IEEE one-area Reliability Test System}

In this section, we apply the proposed storage system's pool strategy model to the IEEE one-area (24-bus) Reliability Test System [29] considering two compressed air energy storage facilities. The characteristics of storage facilities and generators' marginal costs are given in Table VII and Table VIII respectively.

Note that there are other sources of uncertainty in strategic operation of the storage facilities, such as unexpected loss of generation units. In this paper, for the sake of simplicity, the storage facilities are only studied under uncertainty of wind power generation. However, other sources of uncertainty at the cost of increasing the computation burden can also be

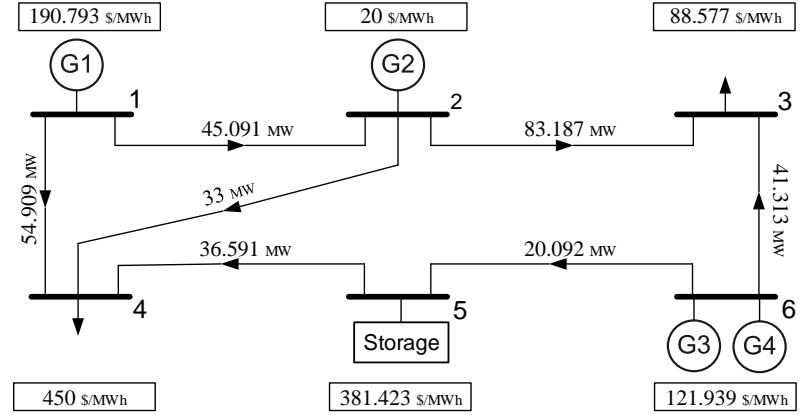

Fig. 4. The line flows and LMPs in Case 3 at hour 17

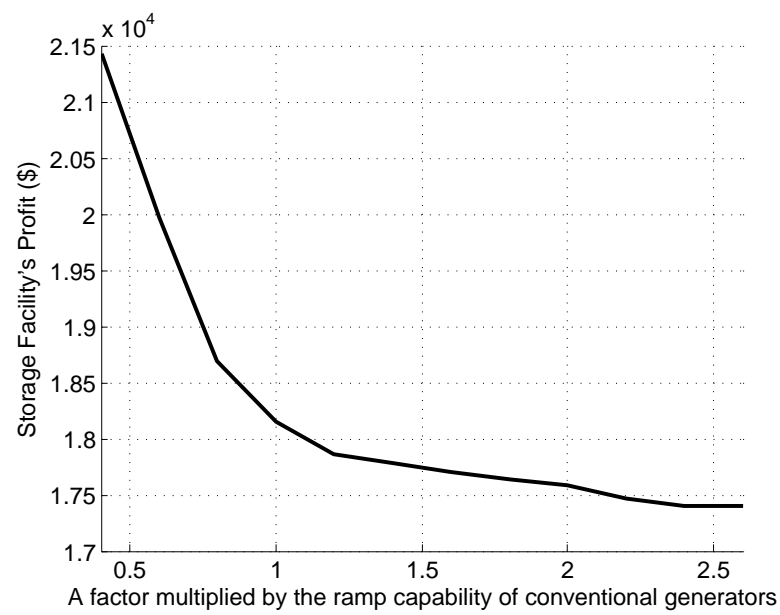

Fig. 5. The storage system's profit versus different levels of total ramp up/down capability of conventional generators

modeled through scenarios [16]. The wind power producer is considered at bus 10 . The wind power forecast follows an identical distribution as in [26] scaled by a factor of four. Similar to [30], we model wind power forecast errors based on the normal distribution. We consider two normal distributions with identical error mean, i.e., zero, but with different standard deviations. In the first one, the standard deviation is $10 \%$, while it is $20 \%$ in the second one, which refers to a more volatile wind power forecast. Then, 1000 samples are generated from each distribution using a MonteCarlo simulation. In the next step, each set of 1000 samples is reduced to 10 scenarios using a backward method described in [31]. The relative distance for the two reduced sets is less than $60 \%$ [32]. The daily expected profit of the storage facilities for the three cases considering both sets of scenarios are provided in Table IX

A comparison of the Base Case and Case 1 reveals that the strategic storage gains more expected profit in the strategic case with respect to the non-strategic one. This profit even increases in Case 2 in which the physical limits of the rest of the fleet, i.e, the ramp limits of conventional generators and the transmission capacity constraints, are considered. Another important observation from the results of this case study is that a comparatively higher wind power volatility results in increasing the expected profit of the strategic storage facility since more ramp resources are needed.

Figure 8 shows that the strategic behavior of storage facility 


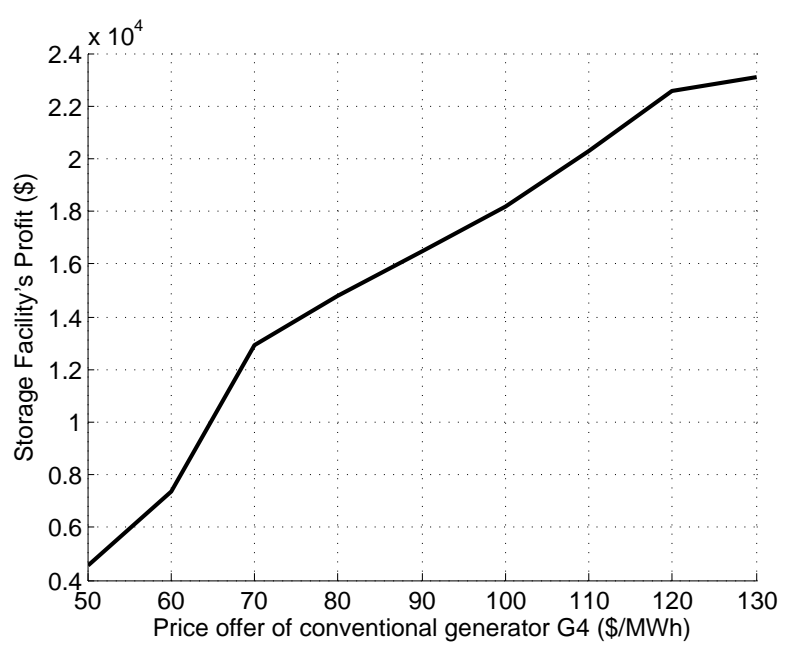

Fig. 6. The storage system's profit versus different price offers of conventional generator $\mathrm{G} 4$

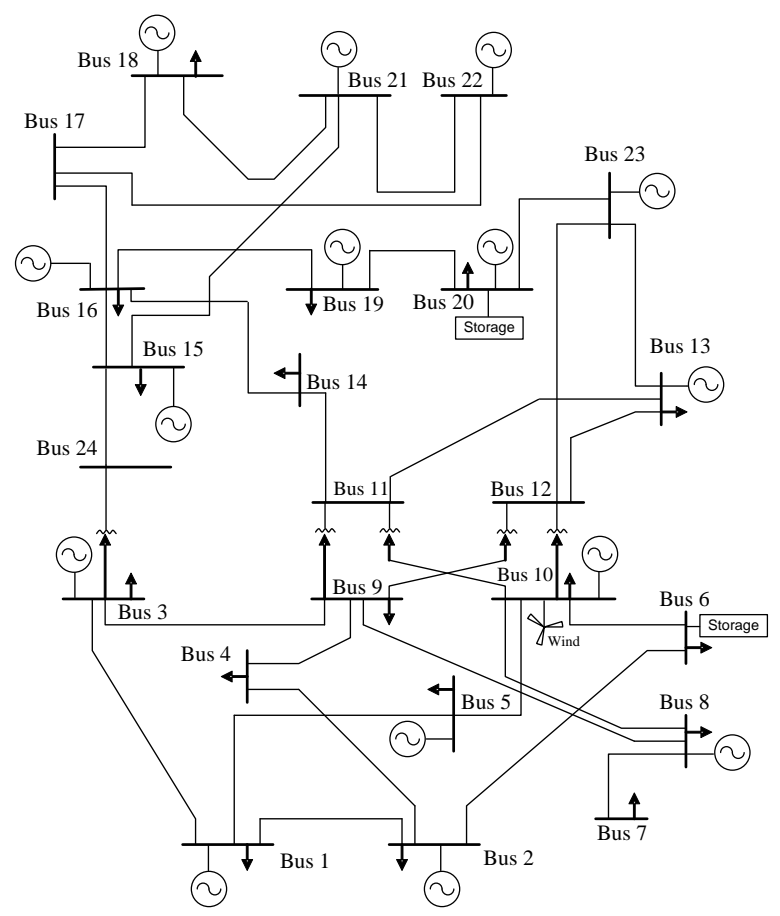

Fig. 7. The IEEE one-area Reliability Test System one-line diagram

decreases the price during charging and increases the price during discharging. The storage facility's impact on market price is higher in discharging compared to charging hours. The reason lies in a fact that the supply curve is relatively steep in discharging compared to charging hours. As shown in Fig. 8, the consideration of transmission lines capacities and conventional generators ramping limits make more opportunity for the storage facility to impact on market prices in Case 2 compared to the first two cases.

\section{CONCLUSION}

This paper proposes a complementarity bi-level approach to derive the most beneficial pool strategy of a price-maker energy storage system through making strategic inter-temporal
TABLE VII

STORAGE SYSTEMS CHARACTERISTICS [28]; THE IEEE ONE-AREA RELIABILITY TEST SYSTEM

\begin{tabular}{ccccccc}
\hline $\begin{array}{c}\text { Storage } \\
\text { system }\end{array}$ & Bus No. & $\begin{array}{c}P_{s}^{\text {dis, max }} \\
(\mathrm{MW})\end{array}$ & $\begin{array}{c}P_{s}^{\text {ch, max }} \\
(\mathrm{MW})\end{array}$ & $\begin{array}{c}E_{s}^{\max } \\
(\mathrm{MWh})\end{array}$ & $\begin{array}{c}M C_{s}^{\text {dis }} \\
(\$ / \mathrm{MWh})\end{array}$ & $\begin{array}{c}M C_{s}^{c h} \\
(\$ / \mathrm{MWh})\end{array}$ \\
\hline 1 & 6 & 100 & 75 & 500 & 17.69 & 0.87 \\
2 & 20 & 100 & 75 & 500 & 17.69 & 0.87 \\
\hline
\end{tabular}

TABLE VIII

GENERATORS' MARGINAL COST; THE IEEE ONE-AREA RELIABILITY TEST SYSTEM

\begin{tabular}{ccc}
\hline Generator & Bus No. & $\begin{array}{c}M C_{g} \\
(\$ / M W h)\end{array}$ \\
\hline G1 & 1 & 48.32 \\
G2 & 2 & 48.32 \\
G3 & 7 & 57.70 \\
G4 & 13 & 78.93 \\
G5 & 15 & 60.11 \\
G6 & 15 & 10.52 \\
G7 & 16 & 10.52 \\
G8 & 18 & 5.47 \\
G9 & 21 & 5.47 \\
G10 & 22 & 1.00 \\
G11 & 23 & 10.52 \\
G12 & 23 & 29.89 \\
\hline
\end{tabular}

arbitrage decisions in a market under limited ramp sources and wind power generation uncertainty. The primal-dual and KKT conditions of the lower-level problems are derived from transforming the proposed bi-level problem into an MPEC that can then be recast as an MILP. In an imperfect competition, impacts of storage system pool strategy on hourly SMCs and generation schedule are presented and discussed. Moreover, effects of physical and financial market conditions such as transmission capacity limits, ramp rate limits of conventional generators, and the smoothness level of supply curve on strategic storage system's decisions are discussed. The storage system was found to adjust its operation strategies to take advantage of existing circumstances in the market.

\section{REFERENCES}

[1] L. Bird, M. Milligan, , and D. Lew, "Integrating variable renewable energy: Challenges and solutions," National Renewable Energy Laboratory, Sep. 2013.

[2] D. Tretheway and L. Xu, "Flexible ramping products," Apr. 2012. [Online]. Available: https://www.caiso.com/Documents/ DraftFinalProposal-FlexibleRampingProduct.pdf

[3] N. Navid and G. Rosenwald, "Ramp capability product design for MISO markets," Jul. 2013. [Online]. Available: https://www.misoenergy.org/Library/Repository/Communication\% 20Material/Key\%20Presentations\%20and\%20Whitepapers/Ramp\% 20Product\%20Conceptual\%20Design\%20Whitepaper.pdf

[4] P. Hockenos, "Energy storage market outlook 2015," Feb. 2015. [Online]. Available: http://www.renewableenergyworld.com/rea/news/ article/2015/02/energy-storage-market-outlook-2015

[5] S. Dahlke, "Grid-scale energy storage for integrating renewable energy: Updates on FERC order 755 and DOE-funded demonstration projects," 2012.

[6] C. O'Dwyer and D. Flynn, "Using energy storage to manage high net load variability at sub-hourly time-scales," IEEE Trans. on Power Syst., vol. 30, no. 4, pp. 2139-2148, Jul. 2015.

[7] S. Sun, M. Dong, and B. Liang, "Distributed real-time power balancing in renewable-integrated power grids with storage and flexible loads," IEEE Trans. on Smart Grid, to be published, 2015.

[8] N. Gast, D. C. Tomozei, and J. Y. Le Boudec, "Optimal generation and storage scheduling in the presence of renewable forecast uncertainties," IEEE Trans. on Smart Grid, vol. 5, no. 3, pp. 1328-1339, May 2014.

[9] P. Harsha and M. Dahleh, "Optimal management and sizing of energy storage under dynamic pricing for the efficient integration of renewable energy," IEEE Trans. on Power Syst., vol. 30, no. 3, pp. 1164-1181, May 2015. 
TABLE IX

RESULTS FOR THREE CASES (THE IEEE RELIABILITY TEST SYSTEM)

\begin{tabular}{cccc}
\hline Case No. & Description & $\begin{array}{c}\text { Storage } \\
\text { expected profit }(\$ 1000)\end{array}$ \\
\cline { 2 - 4 } & & $\sigma=10 \%$ & $\sigma=20 \%$ \\
\hline Base Case & Storage facilities are non-strategic players & 4.72 & 4.93 \\
Case 1 & Storage facilities behave strategically & 14.28 & 15.23 \\
Case 2 & Storage facilities behave strategically enforcing transmission lines & 19.32 & 22.81 \\
& capacities and conventional generators ramping limits & \\
\hline
\end{tabular}

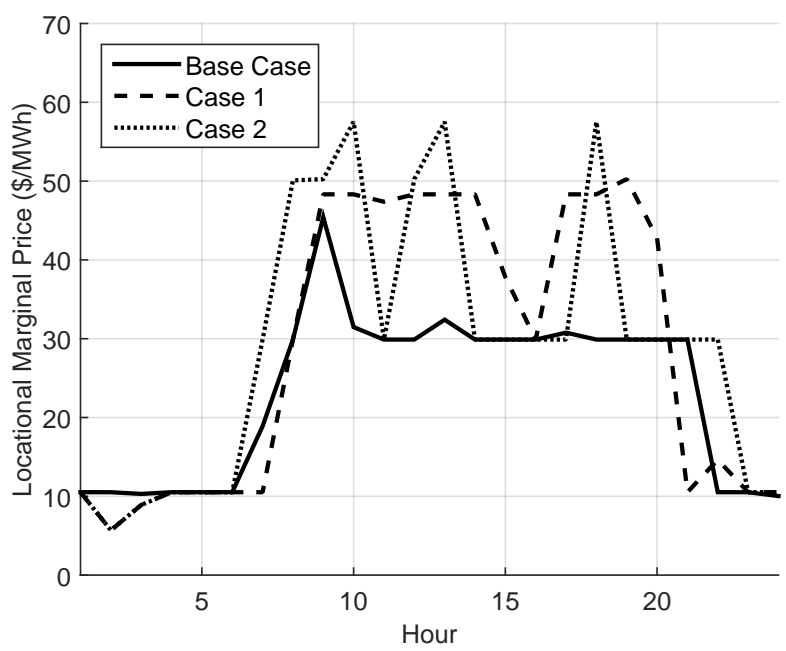

Fig. 8. Average Hourly LMP at bus 6 over wind generation scenarios in three cases

[10] R. Sioshansi, "When energy storage reduces social welfare," Energy Economics, vol. 41, pp. 106-116, Jan. 2014.

[11] E. Nasrolahpour, H. Zareipour, W. D. Rosehart, and S. J. Kazempour, "Bidding strategy for an energy storage facility," Proc. $19^{\text {th }}$ Power Systems Computation Conference (PSCC), Jun. 2016.

[12] H. Mohsenian-Rad, "Coordinated price-maker operation of large energy storage units in nodal energy markets," IEEE Trans. on Power Syst., vol. 31, no. 1, pp. 786-797, Jan. 2016

[13] Sandia National Laboratories, "DOE global energy storage database." [Online]. Available: http://www.energystorageexchange.org/

[14] Alberta Innovates- Energy and Environment Solutions (AI-EES), "\$2 million call for proposals- next generation renewable energy storage technologies," 2014. [Online]. Available: http://albertainnovates. ca/media/22192/ai-ees_energy_storage_2millionfunding.pdf

[15] Alberta Electric System Operator (AESO), "Energy storage integration," 2014. [Online]. Available: http://www.aeso.ca/downloads/Energy_ Storage_Integration_Discussion_Paper.pdf

[16] A. J. Conejo, M. Carrion, and J. M. Morales, Decision Making Under Uncertainty in Electricity Markets. International Series in Operations Research \& Management Science. New York, NY, USA: Springer, 2010.

[17] B. F. Hobbs, C. B. Metzler, and J. S. Pang, "Strategic gaming analysis for electric power systems: An MPEC approach," IEEE Trans. on Power Syst., vol. 15, no. 2, pp. 638-645, May 2000.

[18] A. Gomez-Exposito, A. J. Conejo, and C. Canizares, Electric Energy Systems: Analysis and Operation. CRC Press, 2008.

[19] S. J. Kazempour, A. J. Conejo, and C. Ruiz, "Strategic bidding for a large consumer," IEEE Trans. on Power Syst., vol. 30, no. 2, pp. 848856, Mar. 2015.

[20] E. Nasrolahpour, S. J. Kazempour, H. Zareipour, and W. D. Rosehart, "Strategic sizing of energy storage facilities in electricity markets," IEEE Trans. on Sust. Ener, to be published, 2016.

[21] J. Fortuny-Amat and B. McCarl, "A representation and economic interpretation of a two-level programming problem," The Journal of the Operational Research Society, vol. 32, no. 9, pp. 783-792, Sep. 1981.

[22] C. Ruiz and A. J. Conejo, "Pool strategy of a producer with endogenous formation of locational marginal prices," IEEE Trans. on Power Syst., vol. 24, no. 4, pp. 1855-1866, Nov. 2009.

[23] M. Kazemi, B. Mohammadi-Ivatloo, and M. Ehsan, "Risk-constrained strategic bidding of gencos considering demand response," IEEE Trans. on Power Syst., vol. 30, no. 1, pp. 376-384, Jan. 2015.
[24] S. Wogrin, E. Centeno, and J. Barquin, "Generation capacity expansion in liberalized electricity markets: A stochastic MPEC approach," IEEE Trans. on Power Syst., vol. 26, no. 4, pp. 2526-2532, Nov. 2011.

[25] General Algebraic Modeling System (GAMS), "GAMS platform." [Online]. Available: http://www.gams.com/

[26] E. Nasrolahpour and H. Ghasemi, "A stochastic security constrained unit commitment model for reconfigurable networks with high wind power penetration," Elect. Power Syst. Res., vol. 121, pp. 341-350, Apr. 2015.

[27] S. Shafiee, H. Zareipour, A. N. Knight, A., and B. MohammadiIvatloo, "Risk-constrained bidding and offering strategy for a merchant compressed air energy storage plant," IEEE Trans.s on Power Syst., to be published, 2016.

[28] H. Safaei and D. W. Keith, "Compressed air energy storage with waste heat export: An Alberta case study," Energy Conversion and Management, vol. 78, pp. 114-124, Feb. 2014.

[29] Reliability System Task Force, "The IEEE reliability test system-1996: A report prepared by the reliability test system task force of the application of probability methods subcommittee," IEEE Trans. on Power Syst., vol. 14, no. 3, pp. 1010-1020, Aug. 1999.

[30] G. Liu and K. Tomsovic, "Quantifying spinning reserve in systems with significant wind power penetration," IEEE Trans. on Power Syst., vol. 27, no. 4, pp. 2385-2393, Nov. 2012.

[31] W. L. Oliveira, C. Sagastizabal, D. J. Penna, M. E. Maceira, and J. M. Damazio, "Optimal scenario tree reduction for stochastic stream flows in power generation planning problems," Optimization Methods and Software, vol. 25, pp. 917-936, 2010.

[32] H. Heitsch and W. Romisch, "Scenario reduction algorithms in stochastic programming," Computat. Optimizat. Applicat., vol. 24, no. 2-3, pp. 187-206, Feb. 2003.

Ehsan Nasrolahpour received the B.Sc. degree from the Shahid Chamran University of Ahvaz, Ahvaz, Iran, in 2010, the M.Sc. degree from University of Tehran, Tehran, Iran, in 2013.

$\mathrm{He}$ is currently pursuing his Ph.D. at University of Calgary, Calgary, AB, Canada. His research interests include power systems, electricity markets, and operations research.

Jalal Kazempour (S'08-M'14) received the B.Sc. degree from the University of Tabriz, Tabriz, Iran, in 2006, the M.Sc. degree from Tarbiat Modares University, Tehran, Iran, in 2009, and the Ph.D. degree from the University of Castilla-La Mancha, Ciudad Real, Spain, in 2013, all in electrical engineering.

In 2014, he was a postdoctoral fellow at the Whiting School of Engineering, Johns Hopkins University, Baltimore, MD, USA. He is currently a postdoctoral fellow at the Department of Electrical Engineering, Technical University of Denmark, Kgs. Lyngby, Denmark. His research interests include power systems, electricity markets, optimization, and its applications to energy systems.

Hamidreza Zareipour (S'03-M'07-SM'09) received the Ph.D. degree in electrical engineering from the University of Waterloo, Waterloo, ON, Canada, in 2006.

$\mathrm{He}$ is currently a full Professor with the Department of Electrical and Computer Engineering, University of Calgary, Calgary, AB, Canada. His research focuses on economics, planning, and management of power and energy systems in a deregulated electricity market environment. 
William D. Rosehart (SM'05) received the B.Sc, M.Sc., and Ph.D. degrees in electrical engineering from the University of Waterloo, Waterloo, ON, Canada. Currently, he is the Dean of Schulich School of Engineering at the University of Calgary, Calgary, AB, Canada. His main research interests are in the areas of numerical optimization techniques, power system stability, and modeling power systems in a deregulated environment. 